\title{
Predicting quasicrystals with quantum structural diagrams
}

\author{
Jean Tartas and Emile J. Knystautas \\ Département de Physique, Université Laval, Québec, Canada, G1K 7P4
}

(Received 19 November 1990; accepted 19 February 1991)

\begin{abstract}
Binary and ternary quasicrystals have been successfully separated by means of quantum structural diagrams in the light of new experimental data, and new potential candidates for the quasicrystalline state are presented. A general and simple classification of alloy systems, consistent with the experimental data, is proposed, which allows predictions of any type of binary and ternary quasicrystals. Quantum coordinates are analyzed and interpreted, and suggestions are given for an improvement of the present method.
\end{abstract}

\section{INTRODUCTION}

In the description of the ordering of a solid, quasicrystals are intermediate between the amorphous and crystalline states. They are now considered as a genuine, distinct thermodynamic state and can be found with various symmetries (icosahedral, octagonal, decagonal, dodecagonal) forbidden by classical crystallography and in stable or metastable forms. The quasicrystalline state is usually obtained from the melt, and apart from other experimental factors, its occurrence depends critically on the quenching rate, which can vary greatly with the method used. Nevertheless, a problem of considerable interest is the prediction of which alloy system can potentially give (disregarding quenching constraints) a quasicrystal, within given temperature and composition ranges. This interest is more than academic, since rapid solidification techniques are commonly used today to produce (mostly metastable) alloys with superior properties by providing a higher flexibility in alloy composition through extension of solid solubility limits in nonequilibrium processes.

To predict quasicrystals or to understand where they come from, many theoretical approaches or simple empirical observations have been applied, to date, with a limited success. For instance, although Landau mean field theories (that have been given much attention in the literature) support the existence of quasicrystalline symmetry, they are unable to determine likely candidates for a quasicrystal. Moreover, the interpretation depends on the precision of calculations in the Landau expansion of the system free energy, which has given different and conflicting results. ${ }^{1}$ Also, we should mention the potential predictive ability of the often-encountered structural analogies between the quasicrystalline state and its crystalline counterpart, the Frank-Kasper phase. ${ }^{2}$ This well-known experimental fact is not a universal rule and suffers from many departures.

Although an approach based on first principles calculations would be warranted, in this paper, it is not our intention to discuss or compare the theories advanced so far to justify the existence of quasicrystals. Instead, we present a general analysis of binary and ternary quasicrystals based on the very simple but powerful technique of Quantum Structural Diagrams (QSD) introduced several years ago $^{3}$ and applied successfully to high $T_{c}$ superconductors ${ }^{4}$ and quantum defect structures. ${ }^{5}$ At that time, there were not enough data to permit such a study, which led the authors of Ref. 3 to some limited conclusions about quasicrystals. This is a rigorous test for QSD and, at the same time, indicates the various capabilities and limitations of the present method.

\section{GENERAL ANALYSIS}

\section{A. Description of the present method}

Quantum mechanics has shown that energy levels and many other atomic properties are discretized. If the physical properties (of many multi-components systems) responsible for the formation of the quasicrystalline state are simply related to the atomic properties of the components, then our QSD, when applied properly to these system properties, should reflect this quantization. Assuming there exist such system properties, the main problem is to find what they might be and how they can be related to atomic properties. Only physical insights and trial and error guesses could provide a valuable clue. One approach is to consider the type of atom with respect to its valence electrons, i.e., whether it has $s$ or $p$ or $d$ electrons. This allows a very simple and general classification of an alloy system of any number of components. Let us define an $s$-type atom, one which has only $s$ valence electrons, a $p$-type atom that has only $p$ and possibly $s$ valence electrons and, finally, a $d$-type atom that has at least $d$ valence electrons. Thus, the metallurgical behavior of an atom is dictated first by its $d$ valence electrons, if any, and second by its $p$ and $s$ valence electrons. Thus, one can expect a qualitatively different alloy, depending on whether or not it contains $d$ - or $p$ - or $s$-type components. Indeed, this idea is not new at all, since it forms the basis of the periodic classification scheme of the elements according to their (atomic) chemical or physical properties, 
and we only assume that this extends to (poly-atomic) metallurgical properties. In accordance with this view is the preferential environment that $s, p$ and $d$ elements have in forming certain classes of binary, ternary, and quaternary compounds. ${ }^{6} f$ elements are not considered since $f$ electrons, located in the $n=4$ main shell, are usually not a part of the valence electron configuration that includes more exposed $s, p$ and $d$ electrons from $n=5,6$ or 7 main shells where $n$ is the main quantum number. This can be readily seen from the periodic table of the elements.

A binary (ternary, $\ldots$ ) alloy $\mathrm{A}_{x} \mathrm{~B}_{y}\left(\mathrm{~A}_{x} \mathrm{~B}_{y} \mathrm{C}_{z}, \ldots\right)$ with ordered concentrations $x<y(x<y<z, \ldots)$ will give $9(27, \ldots)$ possible "subgroups": $s s, s p, s d, p s$, $p p, p d, d s, d p, d d(s s s, s s p, s s d, s p s, s p p, s p d, s d s, s d p$, $s d d, p s s, p s p, p s d, p p s, p p p, p p d, p d s, p d p, p d d, d s s$, $d s p, d s d, d p s, d p p, d p d, d d s, d d p, d d d \ldots$ ) . . and so on. Forgetting this ordering, we will have for instance in the binary case the 6 following "groups": $\{1 s 1 p\}$, $\{1 s 1 d\},\{1 p 1 d\},\{2 s\},\{2 p\},\{2 d\}$, which indicates the number of components of each type, irrespective of concentrations. This procedure can be straightforwardly applied to a higher number of components but becomes rather cumbersome when this number is greater than three. However, as QSD essentially relies on experimental data to make predictions, one can hope that some of these groups or subgroups do not in fact occur at all, which simplifies the analysis since predicting them is irrelevant. When the system properties are correctly characterized, for at least some of these groups or subgroups, one can expect distinct (no overlapping) and hopefully localized regions of a QSD.

Unlike groups, the concept of "subgroups" is not necessarily supported by our main ansatz, though it may have practical value, in which case most alloy systems (that give quasicrystals) span composition ranges that lie within the same subgroup. For instance, the alloy system AlMgZn has a composition range involving two subgroups: $d s p$ and $p s d$, which simply means that these two subgroups fail to isolate this alloy system; i.e., it belongs to a unique subgroup. The main reason for using subgroups instead of groups is, if they are to be meaningful, they should show up in QSD in smaller domains than groups would, narrowing the number of good candidates for quasicrystals. Our data will show that this concept has a real validity, which means that quasicrystals occur most often with a rather fixed stoichiometry.

Following Villars et al., ${ }^{3}$ as atomic properties, we used basically their Quantum Coordinates (QC), $X_{\mathrm{MB}}$ and $r^{s p}$, which are, respectively, the electronegativity in the Martynov-Batsanov scale and the Zunger-Cohen pseudopotential $s-p$ radii sum (note that $r^{s p}=r^{s}+r^{p}$ ). $X_{\mathrm{MB}}$ does not depend on system properties, unlike other (e.g.: Pauling) electronegativity scales, which is desirable, and $r^{s p}$ measures the classical turning points of valence electrons incident on atom cores at the Fermi energy. This latter coordinate is very different from the commonly used geometrical radii derived from global structures which, as we stress again, are system properties. These two quantities have proved highly successful in separating binary and ternary compounds into known structures and, as we have stated in the introduction, have served to predict with some success $p s d$ or $d s p$ ternary quasicrystals, in conjunction with Frank-Kasper phases of similar composition and identical structure. As will be seen later, the use of these phases is no longer necessary mainly because enough quasicrystals have been discovered during the last few years to provide reasonable statistics and we believe that these phases are only an indicator of the potential quasicrystalline phase forming ability of an alloy system.

To analyze the data we collected, we basically used linear QC of the system, $\Phi^{s}$ and $\Psi^{s}$, as introduced by Villars:

(i) Binary alloy $\mathrm{A}_{x} \mathrm{~B}_{y}(x<y, x+y=1)$ :

$$
\begin{aligned}
& \Phi_{2}^{s}=x \Phi_{\mathrm{A}}+y \Phi_{\mathrm{B}} \\
& \Psi_{2}^{s}=2 x\left(\Psi_{\mathrm{A}}-\Psi_{\mathrm{B}}\right)
\end{aligned}
$$

(ii) Ternary alloy $\mathrm{A}_{x} \mathrm{~B}_{y} \mathrm{C}_{z}(x<y<z, x+y+z=1)$ :

$$
\begin{aligned}
\Phi_{3}^{s}= & x \Phi_{\mathrm{A}}+y \Phi_{\mathrm{B}}+z \Phi_{\mathrm{C}} \\
\Psi_{3}^{s}= & 2 x\left(\Psi_{\mathrm{A}}-\Psi_{\mathrm{B}}\right)+2 x\left(\Psi_{\mathrm{A}}-\Psi_{\mathrm{C}}\right) \\
& +2 y\left(\Psi_{\mathrm{B}}-\Psi_{\mathrm{C}}\right)
\end{aligned}
$$

Subscripts A, B, and C refer to elemental QC of the alloy. By using (1) and (3), we applied $\Phi^{s}$ to the $s-p$ and $s-p-d$ valence electron number, being, respectively, $N^{s p}$ and $N^{s p d}$ and, by using (2) and (4), $\Psi^{s}$ to $X_{\mathrm{MB}}$, as well as $r^{s p}$. The resulting concentration-averaged quantities will be denoted by brackets, e.g., $\left\langle r^{s p}\right\rangle$. Results of these calculations will be presented later. The present forms of $\Psi^{s}$ as given by (2) and (4) are not physically evident and their generalization to a higher number of components is neither trivial nor automatic. Also, the imposed order $x<y(x<y<z$ in the ternary case) is artificial and so is $\Psi^{s}$, which introduces spurious discontinuities in QSD as soon as the order is reversed, i.e., $y>x$ (or $z>x$ or $z>y$ for ternaries). These discontinuities can cause an alloy to belong to several subgroups or to have discontinuous QC within a same subgroup, for instance $d d$ or $d d p$. Whether $x=y$ or $x=y=z$, one can have 2 or 6 solutions, which calls for an arbitrary choice to be made. Whenever this happened, we chose the one which fell in the area defined by the subgroup given by the other alloys. In practical terms (for predictive purposes), this is not important as long as subgroups resulting from this order are still well defined. Because of the artificiality of an imposed order, forms of $\Psi^{s}$ that get rid of discontinuities and being invariant 
under permutations of $\mathrm{A}, \mathrm{B}$, and $\mathrm{C}$ indices may be more physically interesting. Nevertheless, $\left\langle r^{s p}\right\rangle$ and $\left\langle X_{\mathrm{MB}}\right\rangle$ as given by (2) and (4) have been successful (regarding our results) in separating quasicrystals into subgroups.

\section{B. Presentation of the data}

We collected, according to the best of our knowledge, all ternary and binary quasicrystals found to date (as of September 1990) and listed in Table I and Table II, respectively, along with their fundamental features useful for our analysis. For both tables, the columns present, from left to right, the alloy systems in which quasicrystals have been found, composition domains, stability, quasicrystalline symmetry, and references.

In the first column, alloy systems are arranged alphabetically in decreasing order of their most common concentrations, as indicated at the top of the tables.

TABLE I. Ternary quasicrystals with some of their fundamental characteristics. To read the information, see details in text.

\begin{tabular}{|c|c|c|c|c|c|}
\hline \multirow{3}{*}{$\begin{array}{c}\text { Alloy } \\
\mathrm{A}_{x} \mathrm{~B}_{y} \mathrm{C}_{z} \\
x>y>z\end{array}$} & \multirow{2}{*}{$\begin{array}{c}\text { Composition domains } \\
\{x, y, z\} ; \quad x+y+z=100\end{array}$} & \multirow{2}{*}{\multicolumn{2}{|c|}{ Stability }} & $\begin{array}{l}\text { Symmetry; } \\
\text { subgroups for }\end{array}$ & \multirow{2}{*}{$\begin{array}{r}\text { References } \\
\text { (partial list) }\end{array}$} \\
\hline & & & & $\mathrm{C}_{z} \mathrm{~B}_{y} \mathrm{~A}_{x} ; \quad x>y>z$ & \\
\hline & (a) $91,5,4$ & $\mathrm{~m}$ & $(s)$ & $\mathrm{I}, d p p$ & 11 \\
\hline & (b) $84,2,14$ & $\mathrm{~m}$ & (s) & $\mathrm{I}, p d p$ & 12 \\
\hline 2. $\mathrm{AlCoNi}$ & $75-65,15-20,10-15$ & $\mathbf{s}$ & (m) & $\mathrm{D} 10, d d p$ & 13 \\
\hline 3. $\mathrm{AlCoSi}$ & $75,20,5$ & $\mathrm{~m}$ & (m) & $\mathrm{D} 10, p d p$ & 14 \\
\hline 4. $\mathrm{AlCrCo}$ & $80,13,7$ & $\mathrm{~s}$ & $(?)$ & $\mathrm{I}, d d p$ & 15 \\
\hline 5. $\mathrm{AlCrEr}$ & $86,12,2$ & $\mathrm{~m}$ & $(\mathrm{~m})$ & $\mathrm{I}, d d p$ & 16 \\
\hline 6. $\mathrm{AlCrFe}$ & $86-78,8-16,6$ & $\mathrm{~s}$ & $(s)$ & $\mathrm{I}, d d p$ & $15,17,18$ \\
\hline 7. $\mathrm{AlCrGe}$ & $84-54,15-23,0-23$ & $\mathrm{~m}$ & $(\mathrm{~m})$ & $\mathrm{I}, p d p$ & 19 \\
\hline 8. $\mathrm{AlCrNi}$ & $86,7,7$ & $\mathrm{~m}$ & (m) & $\mathrm{I}, \mathrm{D} 10, d d p$ & 20 \\
\hline 9. $\mathrm{AlCrRu}$ & $79,17,4$ & $\mathrm{~s}$ & $(\mathrm{~s})$ & $\mathrm{I}, d d p$ & 21 \\
\hline \multirow[t]{2}{*}{ 10. $\mathrm{AlCuCo}$} & (a) $70-60,15-20,15-20$ & s & $(\mathrm{m})$ & $\mathrm{D} 10, d d p$ & 13 \\
\hline & (b) $65,15,20$ & $\mathrm{~s}$ & $(\mathrm{~m})$ & $1 \mathrm{D}, d d p$ & 22,23 \\
\hline 11. $\mathrm{AlCuCr}$ & $75-60,15-20,10-20$ & $\mathrm{~s}, \mathrm{~m}$ & $(?)$ & $\mathrm{I}, d d p$ & 24 \\
\hline 12. $\mathrm{AlCuFe}$ & $65,20,15$ & $\mathrm{~s}, \mathrm{~m}$ & $(\mathrm{~m})$ & $\mathrm{I}, d d p$ & 24,25 \\
\hline \multirow[t]{3}{*}{ 13. AlCuMn } & (a) $65,20,15$ & $\mathrm{~m}$ & (m) & $1 \mathrm{D}, d d p$ & 25 \\
\hline & (b) $75-60,15-20,10-20$ & $\mathrm{~m}$ & (m) & $\mathrm{I}, d d p$ & 26,27 \\
\hline & (c) $69,19,12$ & $\mathrm{~m}$ & $(\mathrm{~m})$ & $\mathrm{I}, \mathrm{D} 10, d d p$ & 25 \\
\hline 14. $\mathrm{AlCuNi}$ & $75,15,10$ & $?$ & $(\mathrm{~m})$ & $1 \mathrm{D}, d d p$ & 28 \\
\hline 15. AlCuOs & $65,20,15$ & $\mathrm{~s}$ & $(s)$ & $\mathrm{I}, d d p$ & 26,29 \\
\hline 16. $\mathrm{AlCuRu}$ & $65,20,15$ & s & $(s)$ & $\mathrm{I}, d d p$ & 26,30 \\
\hline 17. $\mathrm{AlCuV}$ & $80-75,10-15,10$ & s & $(?)$ & $\mathrm{I}, d d p$ & 31,32 \\
\hline 18. $\mathrm{AlFeCe}$ & $65,28,7$ & $\mathrm{~m}$ & (s) & $\mathrm{I}, \mathrm{D} 10, d d p$ & 33,34 \\
\hline 19. AlFeMo & $80,11,9$ & $\mathrm{~s}$ & $(s)$ & $\mathrm{I}, d d p$ & 35 \\
\hline 20. AlFeNi & $75-65,15-20,10-15$ & $\mathrm{~m}$ & (m) & $\mathrm{D} 10, d d p$ & 13 \\
\hline 21. AlFeTa & $70,20,10$ & s & $(\mathrm{s})$ & $\mathrm{I}, d d p$ & 36 \\
\hline 22. AlLiAu & $60,30,10$ & $?$ & (m) & $\mathrm{I}, d s p$ & 37 \\
\hline 23. AlLiCu & $60-55,30-35,10$ & $\mathrm{~s}$ & $(s)$ & $\mathrm{I}, d s p$ & 38,39 \\
\hline 24. AlLiZn & $51,32,17$ & $?$ & (s) & $\mathrm{I}, d s p$ & 37 \\
\hline \multirow{2}{*}{ 25. AlMgAg } & (a) $62-35,35,3-30$ & $\mathrm{~m}$ & $(\mathrm{~m})$ & $\mathrm{I}, d p s$ & $37,41,42$ \\
\hline & (b) $30-40,40,30-20$ & $\mathrm{~m}$ & (m) & $\mathrm{I}, d s p$ & 41 \\
\hline 26. $\mathrm{AlMgAu}$ & $60-50,38-48,2$ & $?$ & $(?)$ & $\mathrm{I}, d s p$ & 42 \\
\hline 27. AlMgCr & $78,13,9$ & $\mathrm{~m}$ & (m) & $\mathrm{I}, d s p$ & 43 \\
\hline 28. $\mathrm{AlMgCu}$ & $60-50,35-40,5-10$ & $\mathrm{~m}$ & (m) & $\mathrm{I}, d s p$ & 42,44 \\
\hline 29. AlMgNi & $58-50,40-48,2$ & $?$ & $(\mathrm{~m})$ & $\mathrm{I}, d s p$ & 42 \\
\hline \multirow[t]{2}{*}{ 30. AlMgPd } & (a) $65-53,33-45,2$ & $?$ & $(?)$ & $\mathrm{I}, d s p$ & 42 \\
\hline & (b) $45-50,53-48,2$ & $?$ & $(?)$ & $\mathrm{I}, d p s$ & 42 \\
\hline \multirow[t]{2}{*}{ 31. AlMgPt } & (a) $60-49,38-49,2$ & $?$ & $(s)$ & $\mathrm{I}, d s p$ & 42 \\
\hline & (b) $49,58-49,2$ & $?$ & $(s)$ & $\mathrm{I}, d p s$ & 42 \\
\hline \multirow[t]{2}{*}{ 32. AlMgZn } & (a) $52,38,10$ & $\mathrm{~m}$ & $(\mathrm{~m})$ & $\mathrm{I}, d s p$ & 37 \\
\hline & (b) $20-24,40-38,40-38$ & $\mathrm{~m}$ & $(\mathrm{~m})$ & $\mathrm{I}, p s d$ & $45,46,47$ \\
\hline 33. AlMnCr & $84-78,10-16,6$ & $?$ & $(?)$ & I, $d d p$ & 48,49 \\
\hline 34. AlMnFe & $89-78,9-15,2-7$ & $\mathrm{~m}$ & $(\mathrm{~m})$ & $\mathrm{D} 10, d d p$ & 50,51 \\
\hline 35. AlMnGe & $73-55,20-25,7-20$ & $\mathrm{~m}$ & $(\mathrm{~m})$ & $\mathbf{I}, p d p$ & $19,52,53$ \\
\hline 36. AlMnNi & $80,10,10$ & $?$ & $(\mathrm{~m})$ & $\mathrm{D} 10, d d p$ & 20 \\
\hline 37. AlMnRu & $79,17,4$ & $\mathrm{~s}$ & (s) & $\mathbb{I}, d d p$ & 21 \\
\hline
\end{tabular}


TABLE I. (Continued)

\begin{tabular}{|c|c|c|c|c|c|}
\hline \multirow{2}{*}{$\begin{array}{c}\text { Alloy } \\
\mathrm{A}_{x} \mathrm{~B}_{y} \mathrm{C}_{z} \\
x>y>z\end{array}$} & Composition domains & \multirow{2}{*}{\multicolumn{2}{|c|}{ Stability }} & $\begin{array}{l}\text { Symmetry; } \\
\text { subgroups for }\end{array}$ & \multirow{2}{*}{$\begin{array}{c}\text { References } \\
\text { (partial list) }\end{array}$} \\
\hline & $\{x, y, z\} ; \quad x+y+z=100$ & & & $\mathrm{C}_{z} \mathrm{~B}_{y} \mathrm{~A}_{x} ; \quad x>y>z$ & \\
\hline \multirow[t]{3}{*}{ 38. AlMnSi } & (a) $79-60,20,1-20$ & $\mathrm{~m}$ & $(\mathrm{~m})$ & $\mathrm{I}, p d p$ & $11,54,55$ \\
\hline & (b) $60-50,20,20-30$ & $\mathrm{~m}$ & $(\mathrm{~m})$ & $\mathrm{I}, d p p$ & 56 \\
\hline & (c) $3,82,15$ & $\mathrm{~m}$ & $(\mathrm{~m})$ & $\mathrm{O}, p p d$ & 31,57 \\
\hline 39. AlMnTi & $72,18,10$ & $?$ & (s) & $1, d d p$ & 58 \\
\hline 40. AlNiSi & $80,14,6$ & $?$ & $(\mathrm{~m})$ & $1 \mathrm{D}, p d p$ & 22 \\
\hline 41. AlPdMn & $70,20,10$ & $\dot{s}$ & $(\mathrm{~m})$ & $\mathrm{I}, d d p$ & 59,60 \\
\hline 42. AlPdRe & $70,20,10$ & s & $(\mathrm{s})$ & $\mathrm{I}, d d p$ & 60 \\
\hline 43. $\mathrm{AlRhCu}$ & $75-65,15-20,10-15$ & $\mathrm{~m}$ & (s) & $\mathrm{D} 10, d d p$ & 13 \\
\hline 44. AlRhNi & $75-65,15-20,10-15$ & $\mathrm{~m}$ & (?) & $\mathrm{D} 10, d d p$ & 13 \\
\hline \multirow[t]{3}{*}{ 45. AlSiCr } & (a) $74-62,15-23,11-15$ & $\mathrm{~m}$ & $(\mathrm{~m})$ & $\mathrm{I}, d p p$ & 19,61 \\
\hline & (b) $62-50,15-23,23-27$ & $\mathrm{~m}$ & (m) & $\mathrm{I}, p d p$ & 19,61 \\
\hline & (c) $62,19,19$ & $\mathrm{~m}$ & $(\mathrm{~m})$ & $\mathrm{I}, \mathrm{D} 10, p d p$ & 62 \\
\hline 46. AlvCo & $80,12,8$ & $\mathbf{s}$ & $(?)$ & $\mathrm{I}, d d p$ & 15 \\
\hline 47. AlVFe & $86,8,6$ & s & (s) & $\mathrm{I}, d d p$ & 15 \\
\hline 48. AlVSi & $71,20,9$ & $?$ & (m) & $1, p d p$ & 63 \\
\hline 49. $\mathrm{CrNiSi}$ & $50,30,20$ & $\mathrm{~m}$ & (s) & $\mathrm{Q}, p d d$ & 64,65 \\
\hline 50. $\mathrm{MnNiSi}$ & $50,33,17$ & $?$ & (s) & $\mathrm{I}, p d d$ & 66 \\
\hline 51. PdUSi & $60,20,20$ & $\mathrm{~m}$ & (s) & $\mathrm{I}, p d d$ & $19,67,68$ \\
\hline 52. $\mathrm{TiMnSi}$ & $60,37,3$ & $\mathrm{~s}$ & (m) & $\mathrm{I}, p d d$ & 68 \\
\hline 53. TiNiSi & $58,28,14$ & $\mathrm{~m}$ & (s) & $\mathrm{I}, p d d$ & 69 \\
\hline 54. TiNiV & $67-47,33,0-20$ & $?$ & $(\mathrm{~m})$ & $1, d d d$ & 70 \\
\hline \multirow[t]{2}{*}{ 55. VNiSi } & (a) $58,38,4$ & $?$ & (s) & $\mathrm{O}, \mathrm{D} 12, p d d$ & 71 \\
\hline & (b) $41,36,23$ & $?$ & (s) & $\mathrm{O}, \mathrm{I}, \mathrm{D} 10, p d d$ & 66 \\
\hline 56. $\mathrm{ZnMgGa}$ & $52-40,32-35,16-25$ & $\mathrm{~s}$ & (s) & $\mathrm{I}, p d d$ & $15,37,72$ \\
\hline 57. $\mathrm{ZrTiNi}$ & $60-20,20-60,20$ & $\mathrm{~m}$ & $(\mathrm{~m})$ & $\mathrm{I}, d d d$ & 73 \\
\hline
\end{tabular}

Next, to allow easy comparison, are composition domains $\{x, y\}$ or $\{x, y, z\}$, corresponding to different (combinations of) quasicrystalline symmetries, normalized to $100 \%$. Maximum ranges consistent with concentrations reported in the literature are given. These very often include nominal compositions of the initial alloy from which quasicrystals are experimentally obtained. In the binary case, since $x+y=100$, there is only one free parameter and the notation is in general form: $\left\{x_{\max }-x_{\min }, y_{\min }-y_{\max }\right\}$ with $x_{\max }+$ $y_{\text {min }}=x_{\min }+y_{\max }=100$. In QSD, because of the particular form of (2), these composition domains will give lines. In the ternary case, the general form is $\left\{x_{\max }-x_{\min }, y_{\min }-y_{\max }, z_{\min }-z_{\max }\right\}$ with $x_{\max }+$ $y_{\min }+z_{\min }=x_{\min }+y_{\max }+z_{\max }=100$. Of course, this representation necessarily cannot enclose the whole domain since there are two free parameters in $x+y+$ $z=100$ but, in all cases, most of the data is located well within these bounds. Similarly, this concentration domain would span an area in QSD. However, this would give incomprehensible graphs. To simplify them, one can represent a rectangle in QSD by the diagonal formed by maximum and minimum values of $\mathrm{QC}$, e.g., the line between the points $\left(\left\langle r^{s p}\right\rangle_{\max },\left\langle X_{\mathrm{MB}}\right\rangle_{\max }\right)$, and $\left(\left\langle r^{s p}\right\rangle_{\min },\left\langle X_{\mathrm{MB}}\right\rangle_{\min }\right)$ if the rectangle is located in the positive quadrant of the $\left(\left\langle r^{s p}\right\rangle-\left\langle X_{\mathrm{MB}}\right\rangle\right)$ plane. When $x$ or $y$ or $z$ is fixed, one has a line in QSD and the notation for composition domains in the tables is obvious.

In the third column, we find first the experimental result concerning thermodynamic stability, whether the quasicrystal is metastable $=\mathrm{m}$ or stable $=\mathrm{s}$. As it is ordinarily accepted, metastability means slow transformation to equilibrium phases upon any arbitrarily small amount of heating whereas stability means partial or total resistance to change under heating, below the melting point. On differential scanning calorimetry curves, transformations of given metastable or stable phases translate, respectively, as exothermic and endothermic peaks. Next (only for Table I, see below) we find (in parentheses) the prediction of Villars based on a three-dimensional QC space formed by $^{3}$ :

$$
\begin{gathered}
\langle u\rangle=1 / 3\left(T_{\mathrm{A}} / T_{\mathrm{B}}+T_{\mathrm{A}} / T_{\mathrm{C}}+T_{\mathrm{B}} / T_{\mathrm{C}}\right) ; \\
T_{\mathrm{A}}>T_{\mathrm{B}}>T_{\mathrm{C}} \\
\langle v\rangle=2 / 3\left[r^{s p}(\mathrm{~A})-r^{s p}(\mathrm{C})\right] \\
r^{s p}(\mathrm{~A})>r^{s p}(\mathrm{~B})>r^{s p}(\mathrm{C}) \\
\left\langle\left|N^{s p d}\right|\right\rangle=2 / 3\left[N^{s p d}(\mathrm{~A})-N^{s p d}(\mathrm{C})\right] ; \\
N^{s p d}(\mathrm{~A})>N^{s p d}(\mathrm{~B})>N^{s p d}(\mathrm{C})
\end{gathered}
$$

where $T_{\mathrm{A}}$ is the melting point of $\mathrm{A}$, etc. ... One has similar expressions for the binary case. As it can be seen 
TABLE II. Binary quasicrystals with some of their fundamental characteristics. To read the information, see details in text.

\begin{tabular}{|c|c|c|c|c|}
\hline Alloy & Composition domains & \multirow[b]{2}{*}{ Stability } & $\begin{array}{c}\text { Symmetry; } \\
\text { subgroups for }\end{array}$ & \multirow{2}{*}{$\begin{array}{c}\text { References } \\
\text { (partial list) }\end{array}$} \\
\hline $\mathrm{A}_{x} \mathrm{~B}_{y} ; \quad x>y$ & $\{x, y\} ; \quad x+y=100$ & & $\mathrm{~B}_{y} \mathrm{~A}_{x} ; \quad x>y$ & \\
\hline 1. $\mathrm{AlCo}$ & $86-68,14-32$ & $\overline{\mathrm{m}}$ & $\mathrm{D} 10, d p$ & 74,75 \\
\hline 2. $\mathrm{AlCr}$ & $97-78,3-22$ & $\mathrm{~m}$ & $\mathrm{I}, d p$ & $76,77,78$ \\
\hline 3. $\mathrm{AlFe}$ & $86-74,14-25$ & $\mathrm{~m}$ & $\mathrm{I}, \mathrm{D} 10, d p$ & 79,80 \\
\hline \multirow[t]{2}{*}{ 4. AlMn } & (a) $94-86,6-14$ & $\mathrm{~m}$ & $\mathrm{I}, d p$ & $76,81,82,83$ \\
\hline & (b) $86-75,14-20$ & $\mathrm{~m}$ & $\mathrm{I}, \mathrm{D} 10, d p$ & 84 \\
\hline 5. AlMo & 92,8 & $?$ & $\mathrm{I}, d p$ & 21 \\
\hline 6. AlNi & $86-80,14-20$ & $\mathrm{~m}$ & $\mathrm{D} 10, d p$ & 75,85 \\
\hline 7. AlPd & $80-75,20-25$ & $\mathrm{~m}$ & $\mathrm{D} 10, d p$ & 86 \\
\hline 8. AlPt & 86,14 & $?$ & $\mathrm{D} 10, d p$ & 87 \\
\hline 9. AlRe & $86-78,14-22$ & $\mathrm{~m}$ & $\mathrm{I}, d p$ & 21,88 \\
\hline 10. $A l R u$ & $86-77,14-23$ & $\mathrm{~m}$ & $I, d p$ & 21,81 \\
\hline \multirow[t]{2}{*}{ 11. AlV } & (a) $94-90,6-10$ & $\mathrm{~m}$ & $\mathrm{D} 10, d p$ & 75,78 \\
\hline & (b) $90-78,10-22$ & $\mathrm{~m}$ & $\mathrm{I}, \mathrm{D} 10, d p$ & 75,78 \\
\hline 12. AlW & 92,8 & $?$ & $\mathrm{I}, d p$ & 21 \\
\hline 13. $\mathrm{CoEr}$ & 80,20 & $\mathrm{~m}$ & $\mathrm{I}, d d$ & 89,90 \\
\hline 14. $\mathrm{CrNi}$ & 71,29 & $?$ & $\mathrm{D} 12, d d$ & 91 \\
\hline 15. $\mathrm{CuCd}$ & 61,39 & $?$ & $\mathrm{I}, d d$ & 92 \\
\hline 16. $\mathrm{FeCu}$ & 60,40 & $\mathrm{~m}$ & $\mathrm{I}, d d$ & 93 \\
\hline 17. FeMo & $70-40,30-60$ & $\mathrm{~m}$ & $\mathrm{I}, d d$ & 94 \\
\hline 18. $\mathrm{FeNb}$ & 52,48 & $\mathrm{~m}$ & $\mathrm{D} 10, d d$ & 95 \\
\hline 19. $\mathrm{MnSi}$ & 80,20 & $?$ & $\mathrm{o}, p d$ & 96 \\
\hline 20. $\mathrm{MnTi}$ & $65-33,35-67$ & s & $\mathrm{I}, d d$ & 97,68 \\
\hline 21. $\mathrm{PbBi}$ & 72,28 & $\mathrm{~m}$ & $\mathrm{I}, p d$ & 98 \\
\hline 22. $\mathrm{TiCo}$ & 65,35 & $?$ & $\mathrm{I}, d d$ & 68 \\
\hline 23. TiFe & 65,35 & $\mathrm{~m}$ & $\mathrm{I}, d d$ & 68,99 \\
\hline 24. $\mathrm{TiNi}$ & 65,35 & $?$ & $\mathrm{I}, d d$ & 100,101 \\
\hline 25. VNi & 60,40 & $?$ & $\mathrm{D} 12, d d$ & 101 \\
\hline
\end{tabular}

directly from these equations, these $\mathrm{QC}$ are independent of the elemental concentrations and therefore the prediction is not affected by experimental uncertainties associated with nominal compositions. In Table I, ternary quasicrystals very close to the compound-noncompound boundaries (in these three-dimensional QSD) have received a (?) mark since the prediction could not be made by eye. These three QC have also been highly successful in resolving the compound-noncompound question for several classes of binary and ternary alloys. Here too, quasicrystals constitute a rigorous test for these QSD.

The fourth column gives the quasicrystalline symmetry: I = Icosahedral, D10 = Decagonal, D12 = Dodecagonal, $\mathrm{O}=$ Octagonal, and $1 \mathrm{D}=$ one-dimensional (1D) quasicrystal. The notation I,D10 does not mean necessarily that I and D10 are coexisting phases; they may have occurred separately. It is interesting to note, as it is an experimental result (Penrose tilings of any symmetry may exist in 3D), that quasicrystals with I symmetry are $3 \mathrm{D}$, and those with $\mathrm{O}, \mathrm{D} 10$, and D12 symmetries are 2D. Experimentally, 1D quasicrystals all derive from pseudoD10 in which one of the two quasiperiodic axes is indeed periodic. We do not distinguish between $\mathrm{P}$ or I or F- type icosahedral quasicrystals (Bravais classification of quasicrystals) as this distinction has been found in a very limited number of alloys, e.g., AlCuFe. Next in this column, we find subgroups (from these, groups are easily established) ordered as Villars has done for $p s d$ or $d s p$ quasicrystals. Depending on its composition domain, an alloy system may belong to several subgroups.

Finally, in the last column, a rather limited selection of references is given - whenever possible, the most recent ones. Naturally, since the discovery of quasicrystals, the AlMn system has been by far the most studied, with several hundreds of papers devoted to it. Other much studied systems are AlMnSi and AlLiCu.

\section{Results and discussion}

First, from (4), we computed the $\left\langle r^{s p}\right\rangle-\left\langle X_{\mathrm{MB}}\right\rangle$ QSD for ternary quasicrystals with and without relativistic corrections, ${ }^{7}$ which is a more stringent test than the binary case since there are more subgroups. The relativistic corrections improved slightly the QSD and are included in Fig. 1. Remarkably, these QC separate the ternary subgroups into small, well-defined areas, lending strong support to our starting assumption. These areas 
are significantly smaller than the parallelopiped proposed by Villars for $p s d$ or $d s p$ quasicrystals, which decreases considerably the number of good candidates. This is one of the main findings of the present work. The parallelopiped is the area enclosed within the lines defined by the points $\left(\left\langle r^{s p}\right\rangle\left\langle X_{\mathrm{MB}}\right\rangle\right)=(0.4,-1.0),(-1.0,0.1)$, $(-1.0,1.0)$, and $(0.4,-0.1)$. Part of it is shown in Fig. 1 . Out of the 27 possibilities, only 9 subgroups are actually realized: $d d p(28), d s p(11), p d p(8), p d d$ (6), $d p p$ (4), dps (3), ddd (2), psd (1), and ppd (1), with the number in parentheses indicating how many quasicrystals belong to the subgroup. Strangely enough, the lines corresponding to maximum ranges are nearly parallel in almost all subgroups, including the $d p$ one for binaries. We offer no explanation for this, although it does not seem to be an artifact of our method. Neither $\left\langle N^{s p}\right\rangle$ nor $\left\langle N^{s p d}\right\rangle$ appear to be good parameters in separating subgroups since there is considerable overlap in these numbers, e.g.: for $d d p\left\langle N^{s p}\right\rangle$ is between 2.23 and 3.05 and for $d s p$ this quantity is between 2.05 and 2.71. In the following we enumerate some of the basic observations: (i) about $50 \%$ are of the $d d p$ type, (ii) all contain at least one $d$-type constituent (transition metal), (iii) all quasicrystals in $d d p, d s p, p d p, d p p, d s p$, and psd subgroups have $\mathrm{Al}$ as the main component, (iv) all quasicrystalline symmetries are found, (v) $d s p$ and $p s d$ are I symmetry, and (vi) about $40 \%$ are stable.

There were about 12 out of 33 or $36 \%$ violations in Villars' prediction for stability, which is quite disappointing since a random "prediction" gives $50 \%$ violations. All those cases that involved either a (?) mark (no prediction) or a ? mark (no experimental data) or an $\mathrm{s}, \mathrm{m}$ mark (doubtful data) were excluded from the compilation since the violation cannot be established, that gives 24 cases. One should note that a metastable phase may change in a stable phase with slight composition tuning, so the seven $\mathrm{m}$ (s) cases in Table I could still be correct; that makes, in the best eventuality, 5 out of 33 or $15 \%$ violations. Most stable quasicrystals were close to the compoundnoncompound boundaries while metastable ones were randomly dispersed inside metastability domains. Our interpretation is that, in general, quasicrystals are not the most stable configurations of the system and that they have to come from processes far from equilibrium because slow processes favor the more stable crystalline or close-packed structures. In QSD defined by (5), (6), and (7), the critical parameter for separation was $\langle v\rangle$.

Thermodynamically and structurally, the subgroup overall distribution (in Fig. 1) demonstrates that FrankKasper phases are somewhat less related to quasicrystals than is commonly thought because most of the subgroups lie in part inside the parallelopiped defined by the structure (cI 162), though they are close to the boundaries. Frank-Kasper phases exhibiting (cI 160) structure [where the 2(a) sites in (cI 162) are vacant] are

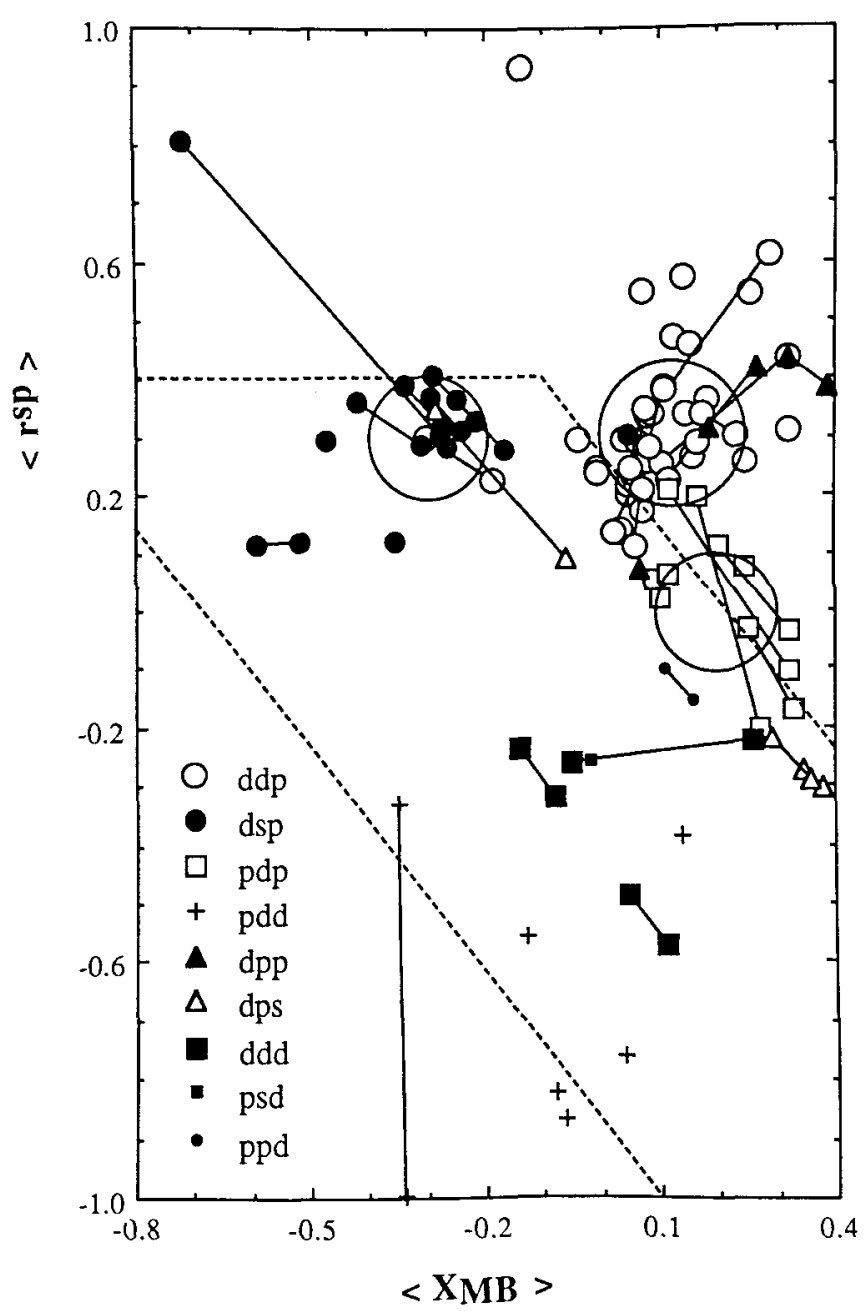

FIG. 1. Quantum structural diagram for ternary quasicrystals subdivided into subgroups using relativistic quantum coordinates $\left\langle r^{s p}\right\rangle$ and $\left\langle X_{\mathrm{MB}}\right\rangle$. Part of the Villars' parallelopiped for $d s p$ or $p s d$ quasicrystals is shown by the broken line. Large circles are the areas used to compute new potential candidates, corresponding to their subgroups. Units are arbitrary.

located far from these boundaries where the whole body of quasicrystals is, indicating that there exist specific physical mechanisms of stability for them. By comparing both tables, one remarks that sometimes suffices a concentration of few $\%$ or less of $d$ element to produce a ternary quasicrystal when it does not exist in binary form. This sudden jump in properties of the alloy reflects the quantization of physical observables responsible for the formation and stability of quasicrystals. QSD are able to distinguish between binding energy differences of the order of $10^{-2} \mathrm{eV}$ or less, which exceeds the precision of any first principles calculations that are of the order of $10^{-1} \mathrm{eV}$ at best. ${ }^{5}$ Our calculated QC show that these energy differences must be very small (probably of the order of $10^{-3} \mathrm{eV}$ or less) in the case of quasicrystals because of the irregular distribution of 
the different quasicrystalline symmetries within each subgroup in both figures.

Admittedly, the separation is not perfect, the violations being clearly $\mathrm{Al}_{75-65} \mathrm{Rh}_{15-20} \mathrm{Cu}_{10-15}$ (alloy\# $=43$, $d d p$ subgroup) which lies in the $d s p$ area, $\mathrm{Al}_{78} \mathrm{Mg}_{13} \mathrm{Cr}_{9}$ (alloy\# $=27, d s p$ subgroup) lying in the $d d p$ area, $\mathrm{Al}_{30-40} \mathrm{Mg}_{40} \mathrm{Ag}_{30-20}$ (alloy\# = 25, dps subgroup) whose part of the range is inside the $d s p$ area and $\mathrm{Ti}_{60} \mathrm{Mn}_{37} \mathrm{Si}_{3}$ (alloy\# = 52, pdd subgroup) that is in the $d d d$ area. The two first cases (alloys\# $=43$ and 27 ) are likely a combined effect of the noninvariant form of (4) under permutations of $\mathrm{A}, \mathrm{B}$, and $\mathrm{C}$ indices and the large uncertainties associated with nominal compositions because, among other sources of errors, there may have been coexisting phases that render exact composition of actual quasicrystals uncertain. This is indeed the case with these two alloys, and since the concentrations of the minor components are nearly equal, there are chances that the actual (exact) values be inverted (with respect to the order $x<y<z$ ), which would give other values of $\mathrm{QC}$. We calculated the QC with a reversed order of the minor components of equal concentrations and found they are placed back into the right areas. Large uncertainties in nominal compositions could also explain the behavior of the two other alloys since exact composition determination has not been made in these. One should note the distant position of AlFeCe $\left(\left\langle r^{s p}\right\rangle=\right.$ $\left.0.94,\left\langle X_{\mathrm{MB}}\right\rangle=-0.13\right)$ is due to the high $r^{s p}$ value of $\mathrm{Ce}$, which has been obtained by a different method. ${ }^{8}$

In short, taking into consideration the fact that there are large uncertainties in nominal compositions, that actual values of QC are approximate, and that (4) may not be the best choice, the separation of ternary quasicrystals into subgroups is convincing.

Shown in Fig. 2, the $\left\langle r^{s p}\right\rangle-\left\langle X_{\mathrm{MB}}\right\rangle$ QSD for binary quasicrystals we computed from (2) was a partial success. There are only 3 subgroups, $d p(12)$ (with $\mathrm{Al}$ as the main component), $d d(11)$ and $p d$ (2) out of a total possibility of nine. The $d p$ subgroup covers a very small area while $d d$ is distributed in a random fashion, even overlapping with $d p$. Clearly, these two QC or the form (2) fail to isolate and characterize completely binary quasicrystals. The dispersion of the $d p$ subgroup is too great to be attributed to the kinds of errors we mentioned above. So, what went wrong: QC or Eq. (2)? Answering such a question is a difficult task since, obviously, the data are too scarce to make any serious conclusion. In this situation, even if one can find good $\mathrm{QC}$ or an equation other than (2) that gives a satisfying separation, it is not convincing unless it can be applied with equal satisfaction to ternaries. With and without the Zunger pseudopotential $s p d$ radii sum: $r^{s p d}=r^{s}+r^{s p}$ which included $d$-type orbitals, we have tried the following linear forms for $\left\langle r^{s p}\right\rangle$ and $\left\langle X_{\mathrm{MB}}\right\rangle$ : the absolute values of (2) and the form $\Psi_{2}^{s}=x y\left|\Psi_{\mathrm{A}}-\Psi_{\mathrm{B}}\right|$, which, by using

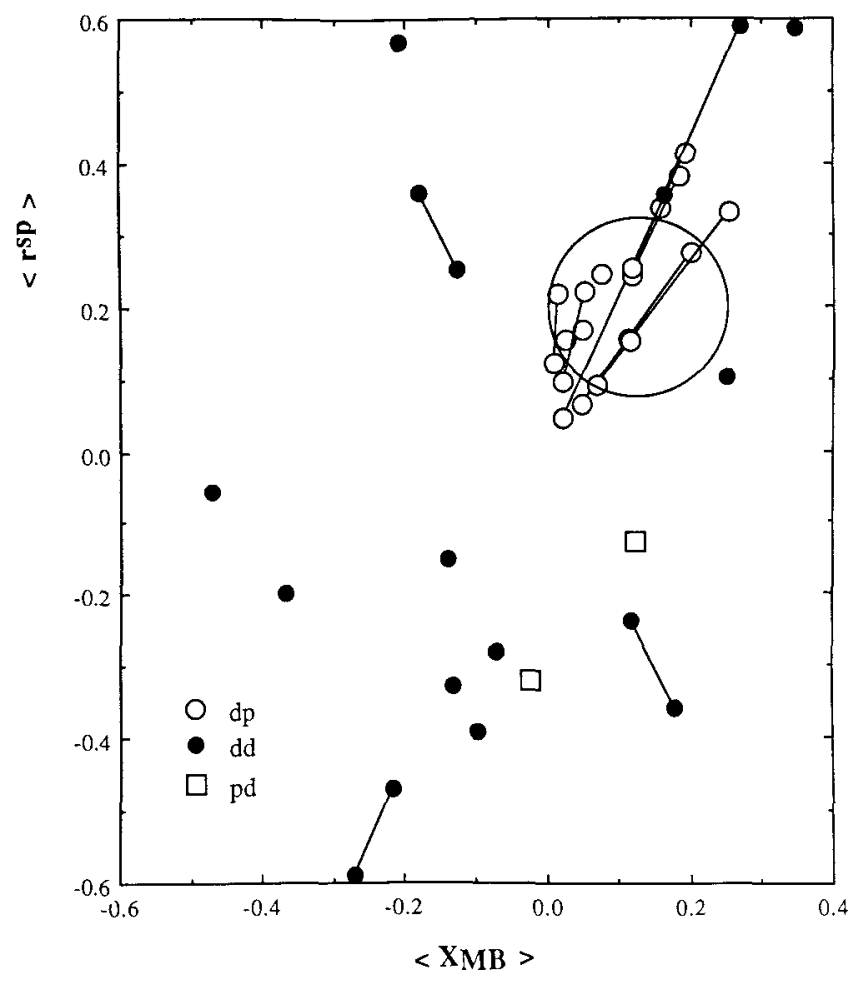

FIG. 2. Quantum structural diagram for binary quasicrystals subdivided into subgroups using relativistic quantum coordinates $\left\langle r^{s p}\right\rangle$ and $\left\langle X_{\mathrm{MB}}\right\rangle$. The large circle is the area used to compute new potential candidates for $d p$ quasicrystals. Units are arbitrary.

the product of concentrations $x$ and $y$, sets the elemental constituents on an equal footing. Unfortunately, none of these attempts was satisfying, but it turned out that $\left\langle N^{s p}\right\rangle$ separated neatly these subgroups: for $d p$ it is between 2.4 and 3 , for $d d$ between 1.4 and 2.0, and for $p d$ between 2.5 and 4.3. However, one should use this separation with caution since it did not work for ternaries. With such a small set of data, this "success" may well be fortuitous.

Villars' prediction of stability for binary alloys is more complex than for ternaries because two distinct cases must be taken into account, when elements are isostructural and when they are not. ${ }^{9}$ The predictions were completely erroneous: most quasicrystals were predicted to be stable! This is why these predictions are not presented in Table II. This failure is no surprise since we had only a partial success for ternaries (using these three QC) and had problems for binaries with $\left\langle r^{s p}\right\rangle$ and $\left\langle X_{\mathrm{MB}}\right\rangle$. It is interesting to note that all but one binary quasicrystals are metastable. Such a difference with ternaries can be explained most simply by the formation of elastic mechanical stresses in quenching the alloy, which increases the cohesion energy. The availability of more different radii allows an easier atomic reorganization relieving stresses to structural configurations of lower total energy, increasing stability in this way. 
It is our feeling that Villars coordinates are still suitable to treat binary quasicrystals mainly because of the undisputed success they achieved with a large number of compounds (several thousands). The effective size of an atom embedded in a matrix has always been a determinant factor in the cohesion energy of the solid and the determination of structures. On the other hand, electronegativities enter into several successful models of alloy formation. For instance, Miedema's semi-empirical model uses differences in electronegativities to predict the sign of the heat of formation in a large variety of binary alloys. Pauling electronegativities are defined directly from the heat of formation of ionic compounds. ${ }^{10}$ Therefore, it seems that one should seek more complicated expressions that use these coordinates. This can be seen in terms of hybridization, which is a linear combination of hydrogenic orbitals. Most $d$ elements have a valence electronic configuration of the form $s d^{n-1}$, where the number of $s-p$ valence electrons is small and nearly constant. Then, for the $d d$ subgroup of binary quasicrystals, hybridization is mostly between $d$-type orbitals and is more complex than hybridization involving $s$ or $p$ orbitals since the number of basic orbitals is greater, five for $d$ orbitals. Then, it is possible that for these quasicrystals, the biggest part of the cohesion energy proceeds by $d d$ hybridization. Hybridization modifies the shape of electronic configurations and hence the effective radius of an atom. Therefore, if this view is accepted, the radius-dependent part of the cohesion energy might comprise complex combinations of atomic radii, hence the need for more elaborate expressions for system QC in terms of elemental QC. No work in this direction has been done so far.

\section{PREDICTIONS AND CONCLUSION}

Prediction with QSD is very simple; it works in the same way as the computations performed to separate the structures or categories into domains of stability. It relies on two critical aspects, the size of these domains which determines how many good candidates we have, and the assumption of typical concentrations, that enables us to calculate the QC of the system. This assumption makes sense if concentrations within a subgroup stay roughly constant, being assessed by the average and relative standard deviation. For each predicted subgroup the relative standard deviation is about $5 \%$. We take the mean value of concentration ranges with an equal statistical weight for each alloy. To ensure reasonable predictions, we choose only well localized subgroups with the highest numbers of data points, that give 4 subgroups which represent about $50 \%$ of binary quasicrystals and $80 \%$ of ternaries found to date. In concentration percentages, for $d p$ binary quasicrystals we have $(x, y)_{\text {mean }}=(85,15)$, and for $d d p, d s p$, and $p d p$ ternary quasicrystals we have, respectively, $(x, y, z)_{\text {mean }}=(73,16,11),(57,37,6)$, and $(69,20,11)$.

Now, for simplicity, we somewhat arbitrarily choose domains to be circles of radius $R$ centered on $\left(\left\langle r^{s p}\right\rangle_{0}\right.$, $\left.\left\langle X_{\mathrm{MB}}\right\rangle_{0}\right)$. For $d p, d d p$, $d s p$, and $p d p$ subgroups we have, respectively, $\left\{\left(\left\langle r^{s p}\right\rangle_{0},\left\langle X_{\mathrm{MB}}\right\rangle_{0}\right), R\right\}=$ $\{(0.2,0.125), 0.125 ;(0.3,0.125), 0.125 ;(0.3,-0.3), 0.1$; $(0.0,0.2), 0.1\}$. These circles are significantly smaller than the actual distribution of data points and lines in Fig. 1 and Fig. 2 in order to ensure a high probability of forming new quasicrystals. Therefore, we do not expect to predict all potential quasicrystals. For all subgroups we require that $\left\langle N^{s p}\right\rangle$ be within the experimental bounds (disregarding extreme cases), say $\left(\left\langle N^{s p}\right\rangle_{\min },\left\langle N^{s p}\right\rangle_{\max }\right)$. For $d p, d d p, d s p$, and $p d p$ subgroups we have, respectively, $\left(\left\langle N^{s p}\right\rangle_{\min },\left\langle N^{s p}\right\rangle_{\max }\right)=\{(2.4,3.0),(2.4,2.9)$, $(2.1,2.6),(2.7,3.0)\}$, that represents narrow ranges that characterize quasicrystals. Therefore, even if $\left\langle N^{s p}\right\rangle$ is not a good separating parameter, its utilization is still meaningful for discriminating between good and bad candidates. For ternary quasicrystals, we use the additional criterion that candidates must be close to the compound-noncompound boundaries or inside domains of metastability, which are parts of the QSD defined by $\langle u\rangle,\langle v\rangle$, and $\left\langle\left|N^{s p d}\right|\right\rangle$. We do not specify whether the potential quasicrystal is stable or not, as this distinction is poorly predicted by Villars. $\left\langle\left|N^{s p d}\right|\right\rangle$ can take only 12 values: $2 / 3^{*}\{0,1,2,3,4,5,6,7,8,9,10,11\}$. For each of these values, we model boundaries by straight lines in the $\langle u\rangle \cdot\langle v\rangle$ plane. With respect to these twelve values, a good candidate must have $\langle u\rangle$ and $\langle v\rangle$ values into these regions: $\left(3 / 2^{*}\left\langle\left|N^{s p d}\right|\right\rangle:\langle u\rangle,\langle v\rangle\right)=$ $\{(0:\langle u\rangle \leqslant 2.1 ;\langle u\rangle \geqslant 2.1$ and $\langle v\rangle \leqslant 0.9),(1:\langle u\rangle \leqslant$ 2.0 and $(\langle v\rangle \geqslant 1.9$ or $\langle v\rangle \leqslant 1.6) ;\langle u\rangle \geqslant 2.0$ and $\langle v\rangle \leqslant 0.7),(2:\langle u\rangle \leqslant 2.6$ and $(\langle v\rangle \geqslant 2.4$ or $\langle v\rangle \leqslant 1.9)$; $\langle u\rangle \geqslant 2.6$ and $\langle v\rangle \leqslant 0.8),(3:\langle u\rangle \leqslant 2.6$ and $\langle v\rangle \leqslant 1.8$; $\langle u\rangle \geqslant 2.6$ and $\langle v\rangle \leqslant 0.7),(4:\langle u\rangle \leqslant 1.8$ and $(\langle v\rangle \leqslant 0.6$ or $0.9 \leqslant\langle v\rangle \leqslant 1.5) ; 1.8 \leqslant\langle u\rangle \leqslant 2.2$ and $\langle v\rangle \leqslant 0.6)$, $(5:\langle u\rangle \leqslant 1.5$ and $(\langle v\rangle \leqslant 0.6$ or $0.9 \leqslant\langle v\rangle \leqslant 1.5)$; $1.5 \leqslant\langle u\rangle \leqslant 2.2$ and $\langle v\rangle \leqslant 0.8),(6,7,8:\langle u\rangle \leqslant 2.5$ and $\langle v\rangle \leqslant 0.7),(9:\langle u\rangle \leqslant 2.8$ and $\langle v\rangle \leqslant 0.8)$, $(10:\langle u\rangle \leqslant 2.0$ and $\langle v\rangle \leqslant 0.6),(11:\langle u\rangle \leqslant 1.8$ and $\langle v\rangle \leqslant 0.4)\}$. The $\langle u\rangle \cdot\langle v\rangle$ domain for $3 / 2^{*}\left\langle\left|N^{s p d}\right|\right\rangle=11$ has been determined by one data point since in this QSD there is no domain of metastability.

The values of all these quantities are those Villars used. ${ }^{3}$ We take 83 elements from the periodic table of the elements, i.e., all elements but halogens $(\mathrm{F}, \mathrm{Cl}, \mathrm{Br}$, $\mathrm{I}, \mathrm{At}$ ), rare gases, hydrogen, and elements heavier than americium. Then, the numbers of $s, p$, and $d$ elements are, respectively, 12, 20, and 51. The lanthanides and actinides have been considered as $d$ elements. The total number of elemental combinations for $d p, d d p, d s p$, and $p d p$ subgroups are, respectively, 1020, 51000, 12240 , and 19000 . It is interesting to note that the two requirements on $\left\langle N^{s p}\right\rangle$ and on $(\langle u\rangle,\langle v\rangle)$ have little effect on 
the number of good candidates in general, except for $p d p$ subgroup. There are only $4 p$ elements that contribute to the predicted quasicrystals in all subgroups but $p d p: \mathrm{Al}$, $\mathrm{Ga}$, In, and $\mathrm{Tl}$, that reflects the ordering of the periodic table. Surprisingly, predicted quasicrystals with In and Tl are at least as numerous as those containing $\mathrm{Al}$ in $d s p$, $p d p$, and $p d$ subgroups and are about four times more numerous than the latter in the $d d p$ subgroup. In this last subgroup the numbers of predicted quasicrystals with $\mathrm{Al}$, $\mathrm{Ga}, \mathrm{In}$, and $\mathrm{Tl}$ as main components are, respectively, 95 , 2, 429, and 435. For convenience, we list only those with $\mathrm{Al}$ and $\mathrm{Ga}$ :

$\mathrm{Al}_{73}(\mathrm{Ti}, \mathrm{V}, \mathrm{Cr})_{16}(\mathrm{Mn}, \mathrm{Fe}, \mathrm{Co}, \mathrm{Ni})_{11}$;

$\mathrm{Al}_{73}(\mathrm{Fe}, \mathrm{Co}, \mathrm{Zn})_{16}(\mathrm{Mn}, \mathrm{Ni}, \mathrm{Rh}, \mathrm{Pd})_{11}$

$\mathrm{Al}_{73}(\mathrm{Mn}, \mathrm{Nb}, \mathrm{Mo}, \mathrm{Tc}, \mathrm{Ru}, \mathrm{Rh}, \mathrm{Ir})_{16}(\mathrm{Co}, \mathrm{Ni})_{11}$;

$\mathrm{Al}_{73}(\mathrm{Ni}, \mathrm{Rh}, \mathrm{Pd}, \mathrm{Ir}, \mathrm{Pt})_{16}(\mathrm{Mn}, \mathrm{Fe})_{11}$

$\mathrm{Al}_{73}(\mathrm{Cu}, \mathrm{Ag}, \mathrm{Cd})_{16}(\mathrm{Rh}, \mathrm{Pd})_{11}$

$\mathrm{Al}_{73}(\mathrm{Fe}, \mathrm{Co}, \mathrm{Cu}, \mathrm{Zn}, \mathrm{Ag}, \mathrm{Cd}, \mathrm{Au})_{16}(\mathrm{Cr}, \mathrm{Mn})_{11}$

$\mathrm{Al}_{73} \mathrm{Mn}_{16} \mathrm{Cr}_{11} ; \mathrm{Al}_{73}(\mathrm{Mn}, \mathrm{Zr} \text {, Tc, } \mathrm{Hf})_{16} \mathrm{Fe}_{11}$;

$\mathrm{Al}_{73}$ (La, Dy, Ho, Er, Tm, Yb, Ac) ${ }_{16} \mathrm{Mn}_{11}$

$\mathrm{Al}_{73} \mathrm{Mn}_{16} \mathrm{Rh}_{11} ; \mathrm{Al}_{73}(\mathrm{Mn}, \mathrm{Fe}, \mathrm{Co}, \mathrm{Ni}, \mathrm{Cu}, \mathrm{Pd})_{16} \mathrm{Ir}_{11}$;

$\mathrm{Al}_{73}(\mathrm{Co}, \mathrm{Zn})_{16} \mathrm{Pt}_{11} ; \mathrm{Al}_{73} \mathrm{Zn}_{16}(\mathrm{Ru}, \mathrm{Ti})_{11}$;

$\mathrm{Al}_{73}(\mathrm{Pd}, \mathrm{Pt})_{16} \mathrm{Co}_{11} ; \mathrm{Al}_{73}(\mathrm{Cd}, \mathrm{Au})_{16} \mathrm{Ni}_{11}$;

$\mathrm{Ga}_{73}(\mathrm{~V}, \mathrm{Ti})_{16} \mathrm{Cr}_{11}$.

For $d s p$ quasicrystals, we have 26 candidates:

$\mathrm{Al}_{57} \mathrm{Be}_{37}(\mathrm{Ce}, \mathrm{Pr})_{6} ; \mathrm{Al}_{57} \mathrm{Mg}_{37}(\mathrm{Cu}, \mathrm{Zn}, \mathrm{Ag}, \mathrm{Cd})_{6}$;

$\mathrm{In}_{57} \mathrm{Mg}_{37}(\mathrm{Y}, \mathrm{La}, \mathrm{Ac})_{6} ; \mathrm{Tl}_{57} \mathrm{Mg}_{37}(\mathrm{Nd}, \mathrm{Pm}, \mathrm{Eu}, \mathrm{Gd}, \mathrm{Tb})_{6}$;

$(\mathrm{In}, \mathrm{Tl})_{57} \mathrm{Mg}_{37}(\mathrm{Dy}, \mathrm{Ho}, \mathrm{Er}, \mathrm{Tm}, \mathrm{Yb}, \mathrm{Lu})_{6}$.

For $p d p$ quasicrystals, we have 86 candidates:

$(\mathrm{Al}, \mathrm{Ga})_{69}(\mathrm{~V}, \mathrm{Cr})_{20}(\mathrm{C}, \mathrm{Si})_{11}$;

$\mathrm{Al}_{69}(\mathrm{Mn}, \mathrm{Fe}, \mathrm{Co}, \mathrm{Rh}, \mathrm{Ir})_{20}(\mathrm{C}, \mathrm{Si})_{11}$;

$\mathrm{Al}_{69} \mathrm{Ag}_{20} \mathrm{Te}_{11} ; \mathrm{Al}_{69}(\mathrm{Ti}, \mathrm{Zr}, \mathrm{Nb}, \mathrm{Mo}, \mathrm{Cd})_{20} \mathrm{Si}_{11}$;

$\mathrm{Al}_{69}(\mathrm{Zn}, \mathrm{Cd})_{20} \mathrm{Ge}_{11} ; \mathrm{Al}_{69}(\mathrm{Cu}, \mathrm{Ag})_{20} \mathrm{As}_{11}$;

(In, $\mathrm{Tl})_{69}(\mathrm{Ti}, \mathrm{V}, \mathrm{Cr})_{20}(\mathrm{Sn}, \mathrm{Pb})_{11}$;

$\mathrm{In}_{69}(\mathrm{Nb}, \mathrm{Mo}, \mathrm{Hf}, \mathrm{Ta}, \mathrm{W})_{20}(\mathrm{Ge}, \mathrm{Sn})_{11}$;

$\mathrm{In}_{69}(\mathrm{Mo}, \mathrm{Au})_{20}(\mathrm{Sb}, \mathrm{Bi})_{11} ; \mathrm{In}_{69}(\mathrm{Cr}, \mathrm{Ni}, \mathrm{Cu}, \mathrm{Ag})_{20} \mathrm{Bi}_{11}$;

$\mathrm{In}_{69}(\mathrm{Sc}, \mathrm{Y}, \mathrm{Zr}, \mathrm{La})_{20} \mathrm{Ge}_{11}$;

$\mathrm{In}_{69}(\mathrm{Co}, \mathrm{Nb}, \mathrm{Mo})_{20} \mathrm{~Pb}_{11} ; \mathrm{In}_{69}(\mathrm{Nb}, \mathrm{Ru}, \mathrm{Rh}, \mathrm{Pt})_{20} \mathrm{Sb}_{11}$;

$\mathrm{In}_{69}(\mathrm{Ag}, \mathrm{Au})_{20} \mathrm{Po}_{11} ; \mathrm{Tl}_{69}(\mathrm{Nb}, \mathrm{Mo}, \mathrm{Ta})_{20}(\mathrm{Sn}, \mathrm{Pb})_{11}$;

$\mathrm{Tl}_{69}(\mathrm{Nb}, \mathrm{Mo})_{20}(\mathrm{Sb}, \mathrm{Bi})_{11} ; \mathrm{Tl}_{69} \mathrm{Cr}_{20} \mathrm{Bi}_{11}$;

$\mathrm{Tl}_{69} \mathrm{Mo}_{20} \mathrm{~Pb}_{11} ; \mathrm{Tl}_{69} \mathrm{Pd}_{20} \mathrm{Sb}_{11}$.

Finally, for $d p$ binary quasicrystals, we have 65 candidates:

(Al, Ga, In, Tl $)_{85}(\mathrm{Ti}, \mathrm{V}, \mathrm{Cr}, \mathrm{Nb}, \mathrm{Mo}, \mathrm{Tc}, \mathrm{Ru}, \mathrm{Rh}, \mathrm{Pd}, \mathrm{Ta}, \mathrm{Re}$, Os, Ir, Pt $)_{15}$; $(\mathrm{Al}, \mathrm{Ga})_{85}(\mathrm{Mn}, \mathrm{Fe})_{15}$;

(In, $\mathrm{Tl})_{85} \mathrm{Hf}_{15} ;(\mathrm{In}, \mathrm{Tl})_{85} \mathrm{Zr}_{15} ; \mathrm{Al}_{85} \mathrm{~W}_{15}$

One should note that these lists contain (not necessarily all) quasicrystals already found, that have been included for reference. We do not expect that all of these predictions will be verified and that all new quasicrystals (with respect to their subgroups) will be present in these lists. Also, we cannot determine composition ranges since we have used fixed values of concentrations. Nevertheless, the most important (and surprising) point of our study is that we find a good number of quasicrystals that contain $\mathrm{Ga}$, In, and $\mathrm{Tl}$ as main components.

In conclusion, we have presented a general analysis of known ternary and binary quasicrystals and found new potential candidates by means of quantum structural diagrams. To check some of the predictions, further experimental work is in progress.

\section{REFERENCES}

1. M. Ronchetti, Philos. Mag. B 56, 237 (1987).

2. K. H. Kuo, Key Eng. Mater. 13-15, 219 (1987).

3. P. Villars, J. C. Phillips, and H. S. Chen, Phys. Rev. Lett. 57, 3085 (1986) and references therein.

4. P. Villars and J. C. Phillips, Phys. Rev. B 37, 2345 (1988).

5. J. C. Phillips, Phys. Rev. B 37, 2483 (1988).

6. P. Villars and F. Hullinger, J. Less-Common Met. 132, 289 (1987).

7. S. B. Zhang, M. L. Cohen, and J. C. Phillips, Phys. Rev. B 36, 5861 (1987).

8. P. Villars, J. Less-Common Met. 92, 215 (1983).

9. P. Villars, J. Less-Common Met. 109, 93 (1985).

10. J.A. Alonso and N. H. March, in Electron in Metals and Alloys (Academic Press, London, 1989).

11. T. Rajasekharan, R. Gopalan, D. Akhtar, and D. Banerjee, Scripta Metall. 21, 289 (1987).

12. R. Gopalan, D. Akhtar, and T. Rajasekharan, Z. Metallk. 81, 111 (1990).

13. A-P. Tsai, A. Inoue, and T. Masumoto, Mater. Trans. JIM 30, 463 (1989).

14. J. Menon and C. Suryanarayana, Mater. Trans. JIM 30, 878 (1989).

15. D. W. Lawther, R. A. Dunlap, and V. Srinivas, Can. J. Phys. 67, 463 (1989).

16. D. A. Lilienfeld, in Fundamentals of Beam-Solid Interactions and Transient Thermal Processing, edited by M. J. Aziz, L. E. Rehn, and B. Stritzker (Mater. Res. Soc. Symp. Proc. 100, Pittsburgh, PA, 1988), p. 45.

17. R. Maineila, V. Florescu, A. Jianu, and A. Badescu, Phys. Status Solidi 109, 61 (1988).

18. R. A. Dunlap, D. W. Lawther, and D. J. Lloyd, Phys. Rev. B 38, 3649 (1988).

19. A. Inoue, H. M. Kimura, T. Masumoto, A.P. Tsai, and Y. Bizen, J. Mater. Sci. Lett. 6, 771 (1987).

20. W. L. Zhou, X.Z. Li, and K. H. Kuo, Scripta Metall. 23, 1571 (1989).

21. P. A. Bancel and P. A. Heiney, J. de Physique, Colloq. 47, C3-341 (1986).

22. L. X. He, X. Z. Li, Z. Zhang, and K. H. Kuo, Phys. Rev. Lett. 61, 1116 (1988).

23. H. Zhang and K. H. Kuo, Scripta Metall. 23, 355 (1989).

24. A-P. Tsai, A. Inoue, and T. Masumoto, J. Mater. Sci. Lett. 7, 322 (1988).

25. S. Ebalard and F. Spaepen, J. Mater. Res. 5, 62 (1990).

26. A-P. Tsai, A. Inoue, and T. Masumoto, Mater. Trans. JIM 30, 666 (1989).

27. J. Eckert, L. Schultz, and K. Urban, Appl. Phys. Lett. 55, 117 (1989).

28. G. Van Tendeloo, C. Van Heurck, and S. Amelinckx, Solid State Commun. 71, 705 (1989). 
29. A-P. Tsai, A. Inoue, and T. Masumoto, Jpn. J. Appl. Phys. 27, L1587 (1988).

30. K. Hiraga, M. Hirabayashi, A-P. Tsai, A. Inoue, and T. Masumoto, Philos. Mag. Lett. 60, 201 (1989).

31. A-P. Tsai, A. Inoue, Y. Bizen, and T. Masumoto, Acta Metall. 37, 1443 (1989).

32. J. M. Dubois, M. de Boissieu, and A. Pianelli, Scripta Metall. 23, 1069 (1989).

33. L. Y. Yang, J. G. Zhao, W.S. Zhan, C. Y. Yang, Y. Q. Zhou, and K. K. Fung, J. Phys. F 17, L97 (1987).

34. L. M. Angers, L.D. Marks, J. R. Weertman, and M.E. Fine, in Materials Problem Solving with the Transmission Electron Microscope, edited by L. W. Hobbs, K. H. Westmacott, and D. B. Williams (Mater. Res. Soc. Symp. Proc. 62, Pittsburgh, PA, 1986), p. 255.

35. V. Srinivas, M. E. McHenry, and R. A. Dunlap, Phys. Rev. B 40, 9590 (1989).

36. A-P. Tsai, A. Inoue, and T. Masumoto, Jpn. J. Appl. Phys. 27, L5 (1988).

37. H. S. Chen, J. C. Phillips, P. Villars, A. R. Kortan, and A. Inoue, Phys. Rev. B 35, 9326 (1987).

38. B. Dubost, J-M. Lang, M. Tanaka, P. Sainfort, and M. Audier, Nature 324, 48 (1986).

39. W. A. Cassada, Y. Shen, S. J. Poon, and G. J. Shiflet, Phys. Rev. B 34, 7413 (1986).

40. S. Baranidharan, M. Sundaramoorthy, J. A. Sekhar, E. S. R. Gopal, and V. Sasisekharan, Phase Trans. 16-17, 615-620 (1989).

41. A. Inoue, K. Nakano, Y. Bizen, T. Masumoto, and Ho Sou Chen, Jpn. J. Appl. Phys. 27, L944 (1988).

42. A. Inoue, K. Nakano, T. Masumoto, and Ho Sou Chen, Mater. Trans. JIM 30, 200 (1989).

43. N. K. Mukhopadhyay, Mater. Forum 13, 228 (1989).

44. J. L. Wagner, B. D. Biggs, K. M. Wong, and S.J. Poon, Phys. Rev. B 38, 7436 (1988).

45. H. S. Chen and A. Inoue, Scripta Metall. 21, 527 (1987).

46. T. Shibuya, K. Kimura, and S. Takeuchi, Jpn. J. Phys. A 27, 1577 (1988).

47. H. Yamane, K. Kimura, T. Shibuya, and S. Takeuchi, Mater. Sci. Forum 22-24, 539 (1987).

48. A. Sadoc, J. Physique, Colloq. 47, C3-1003 (1986).

49. C. Zhenhua, W. Yun, Z. Duosan, and J. Xiangyang, Scripta Metall. Mater. 24, 599-604 (1990).

50. R.J. Schaefer, Scripta Metall. 20, 1187 (1986).

51. R. Xu, R. D. Werkman, I. Vince, P. J. Shurer, and F. Van der Woude, Hyperfine Interact. 45, 403 (1988).

52. A. Sadoc, A. M. Flank, and P. Lagarde, Physica B 158, 60 (1989).

53. A. Sadoc, J. Non-Cryst. Solids 106, 166 (1988).

54. C. Antonione and L. Battezzati, J. Less-Common Met. 145, 421 (1988).

55. C. Berger, K. Hasselbach, J. C. Lasjaunias, C. Paulsen, and P. Germi, J. Less-Common Met. 145, 565 (1988).

56. R. A. Dunlap, M. E. McHenry, V. Srinivas, D. Bahadur, and R. C. O'Handley, Phys. Rev. B 39, 4808 (1989).

57. N. Wang and K. H. Kuo, Philos. Mag. Lett. 61, 63 (1990).

58. A. R. Yavari and J. L. Verger-Gaury, J. Mater. Sci. 23, 3383 (1988).

59. A-P. Tsai, A. Inoue, Y. Yokoyama, and T. Masumoto, Philos. Mag. Lett. 61, 9 (1990).

60. A-P. Tsai, A. Inoue, Y. Yokoyama, and T. Masumoto, Mater. Trans. 31, 98 (1990).

61. M. E. McHenry, V. Srinivas, D. Bahadur, R. C. O'Handley, D. J. Lloyd, and R. A. Dunlap, Phys. Rev. B 39, 3611 (1989).

62. H. Zhang, D. H. Wang, and K.H. Kuo, J. Mater. Sci. 24, 2981 (1989).

63. H. Yamane, K. Kimura, T. Shibuya, and S. Takeuchi, Mater. Sci.
Forum 22-24, 539 (1987).

64. N. Wang, H. Chen, and K. H. Kuo, Phys. Rev. Lett. 59, 1010 (1987).

65. D. Shechtman, Phys. Rev. Lett. 53, 1951 (1984).

66. K. H. Kuo, C. Dong, D. S. Zhou, Y.X. Guo, Z. K. Hei, and D. X. Li, Scripta Metall. 20, 1695 (1986).

67. C. Antonione, L. Battezzati, F. Marino, and R. Marazzone, J. Less-Common Met. 154, 169 (1989).

68. K. F. Kelton, Phase Trans. 16-17, 367 (1989).

69. R. A. Dunlap, M.E. McHenry, and R. C. O'Handley, J. Appl. Phys. 64, 5956 (1988).

70. Z. Zhang and K. H. Kuo, Mod. Phys. Lett. B 1, 89 (1987).

71. N. Wang, H. Chen, and K. H. Kuo, Phys. Rev. Lett. 59, 1010 (1987).

72. W. Ohashi and F. Spaepen, Nature 330, 555 (1987).

73. S. A. Sibertsev, V. N. Chebotnikov, V. V. Molokanov, and Yu. K. Kovneristyi, Pis'ma Zh. Eksp. Teor. Fiz 47, 644 (1988)

74. J. Menon and C. Suryanarayana, Scripta Metall. 22, 1125 (1988).

75. R. A. Dunlap and K. Dini, J. Phys. F 16, 11 (1986).

76. S. R. Nishitani, K. N. Ishihara, K. F. Kobayashi, and P. H. Shingu, Mater. Sci. Eng. 99, 443 (1988).

77. H. Zhang, D. H. Wang, and K. H. Kuo, Phys. Rev. B 37, 6220 (1988).

78. D. W. Lawther, D. J. Lloyd, and R. A. Dunlap, Mater. Sci. Eng. A 123, 33 (1990).

79. B. Rauschenbach and V. Heera, J. Mater. Sci. Lett. 6, 401 (1987).

80. K. Hohmuth, V. Heera, and B. Rauscheenbach, Nucl. Instr. Meth. Phys. Res. B 39, 136 (1989).

81. D. M. Follstaedt and J. A. Knapp, Mater. Sci. Eng. 90, 1 (1987).

82. L. A. Bendersky, Mater. Sci. Eng. 99, 331 (1988).

83. D. M. Follstaedt and J. A. Knapp, Mater. Sci. Eng. 99, 367 (1988).

84. M. Harmelin and K. Yu-Zhang, J. Less-Common Met. 145, 411 (1988).

85. X. Z. Li and K. H. Kuo, Philos. Mag. Lett. 58, 167 (1988).

86. G.P. Van Bakel, P.M. Bronsveld, and J.Th. M. De Hosson, J. Physique Coll. C8-265 (1989).

87. P. A. Bancel, P. A. Heiney, P. W. Stephens, A. I. Goldman, and P. M. Horn, Phys. Rev. Lett. 54, 2422 (1985).

88. J. A. Knapp and D. M. Follstaedt, in Fundamentals of Beam-Solid Interactions and Transient Thermal Processing, edited by M.J. Aziz, L. E. Rehn, and B. Stritzker (Mater. Res. Soc. Symp. Proc. 100, Pittsburgh, PA, 1988), p. 597.

89. M. E. McHenry and R. C. O'Handley, in Plasma Processing and Synthesis of Materials, edited by D. Apelian and J. Szekely (Mater. Res. Soc. Symp. Proc, 98, Pittsburgh, PA, 1987), p. 363.

90. L. Hua, J. Shouting, Q. Meiving, S. Yicheng, and R. C. O'Handley, Acta Metall. Sin. 24, A131 (1988).

91. T. Ishimasa, H. U. Nissen, and Fukano, Phys. Rev. Lett. 55, 511 (1985).

92. L. A. Bendersky and F. S. Biancaniello, Scripta Metall. 21, 531 (1987).

93. L. J. Huang, Q. M. Chen, B. X. Liu, Y.D. Fan, and H-D. Li, in Processing and Characterization of Materials Using Ion Beams, edited by L. E. Rehn, J. Greene, and E. A. Smidt (Mater. Res. Soc. Symp. Proc. 128, Pittsburgh, PA, 1989), p. 225.

94. C. H. Shang, J. Li, H-D. Li, and B. X. Liu, J. Phys. F 18, L169 (1988).

95. A. Q. He, Q. B. Yang, and H.Q. Ye, Philos. Mag. Lett. 61, 69 (1990).

96. W. Cao, H. Q. Ye, and K. H. Kuo, Phys. Status Solidi 107, 511 (1988).

97. P. C. Gibbons, K. F. Kelton, L. E. Levine, and R. B. Phillips, Phase Trans. 16-17, 239 (1989).

98. J. A. Sekhar, P. V. Rao, and R. Trivedi, Scripta Metall. 21, 543 (1987). 
99. P. Mandal, A. K. Singh, and O. N. Srivastava, Cryst. Res. Technol. $\quad$ 101. Q. B. Yang, Philos. Mag. Lett. 57, 171 (1988). 23, K139 (1988).

100. C. Dong, Z. K. Hei, L. B. Wang, Q. H. Song, Y. K. Wu, and K. H. Kuo, Scripta Metall. 20, 1155 (1986). 